\title{
Effects of Critical Thinking Disposition and Empathy on Cultural Competency in Dental Hygiene Students
}

\author{
Ji-Min Hwang and Ji-Hyoung Han ${ }^{1, \dagger}$ \\ Department of Dental Hygiene, Baekseok Culture University, Cheonan 31065, \\ 'Department of Dental Hygiene, Suwon Science College, Hwaseong 18516, Korea
}

This study investigated the effects of critical thinking and empathy on the cultural competence of dental hygienists and students. A total of 529 dental hygiene students were randomly sampled and included as subjects. PASW Statistics for Windows ver. 18.0 was used to obtain the following results. Among the critical thinking sub-domains, cognitive integration was the highest and the lowest. Empathic ability had the highest acceptance factor among the sub-domains. Cultural competence was the highest among the sub-domains, while cultural knowledge was the lowest. According to their general characteristics, subject age, grade, religion, and economic level influenced the cultural capacity. Cultural awareness and sensitivity were high when there were foreign visiting experiences. Cultural awareness, sensitivity, skills, and knowledge were high when subjects had experienced multicultural education $(\mathrm{p}<0.05)$. Cultural awareness, sensitivity, skill, experience, and knowledge were correlated with critical thinking and cultural competence, among which cultural sensitivity showed the highest correlation $(p<0.001)$. There was a correlation between cultural awareness and sensitivity, skill, and experience among the empathy and cultural competency sub-domains $(p<0.001)$. The factors influencing cultural awareness included intellectual integration, openness, prudence, and perspective-taking $(p<0.001)$. The factors influencing cultural sensitivity included intellectual integration, openness, and empathic concern $(p<0.001)$. The factors influencing cultural skill included intellectual integration, creativity, and conductivity $(\mathrm{p}<0.001)$. The factors influencing cultural experience included prudence, objectivity, perspective-taking, and personal distress $(p<0.001)$. Finally, the factors influencing cultural knowledge included creativity and conductivity $(p<0.001)$. The results indicate that dental hygiene students should be equipped with cultural competence to enhance critical thinking and empathy required by the modern society and optimized dental hygiene courses should be provided for multicultural subjects.

Key Words: Critical thinking, Cultural competency, Empathy

\section{Introduction}

The increasing communication and migration of citizens between countries ${ }^{1)}$ has led to increasing numbers of foreign workers, immigrants by marriage, study-abroad students, Koreans with foreign citizenship, and refugees ${ }^{2)}$, which led Korea to become a multinational, multicultural society. At the end of 2016, 2,048,441 foreigners resided in Korea, an increase of $8.5 \%$ over 2015 levels and a $9.26 \%$ annual increase in the past 5 years ${ }^{3)}$. In particular, the medical tourism industry has been actively pursued following the amendments to the Medical Services Act in $2009^{4}$; the eligible recipients of this service have since expanded to foreigners. When people from multiple cultures come together, differences arise in their languages, religions, ways of living, thought processes, and values. These differences typically lead to a diverse range of conflicts and issues, ${ }^{5,6}$. In the medical services sector, foreign recipients tend to show different levels of understanding in the experience and knowledge of the condition, health promotion behaviors, and usage behaviors of medical institutions. Care providers face problems such as a lack of communication and understanding as well as social bias ${ }^{7)}$. Therefore, medical services requires a mature understanding and execution of cultural diversity. 
These issues can be solved with cultural capacity, which refers to the understanding and interaction between multicultural people in terms of their beliefs, values, norms, and behaviors, as well as the acquisition and response to such skills ${ }^{5)}$. Going forward, dental hygiene students who must provide dental health services to multicultural patients in the clinical setting must ensure that they have the cultural capacity to resolve and improve issues regarding the oral health of these patients ${ }^{7,8)}$. Cultural capacity begins with an open attitude and flexible way of thinking to understand and accept cultural diversity $^{9)}$. Therefore, it is important to understand the thoughts and perspectives of people in different cultures and communicate with them in a logical manner. Moreover, it is important to adopt an attitude of excluding biases and making decisions based on rationale and evidence. In other words, critical thinking is required ${ }^{10-12)}$. Critical thinking is the ability to evaluate and make decisions in a logical and fair manner ${ }^{13)}$. Critical thinking is a mandatory aspect in analyzing patient information about and applying appropriate problem-solving processes throughout the dental hygiene process and is important in improving communication ability, task execution skills, and the quality of patient care.

Moreover, understanding, consideration, and respect are all related to empathic ability, at the core of effective communication $^{7)}$. Empathic ability, which refers to the ability to understand and share one's thoughts, emotions, behaviors, and experiences, is based on cultural sensitivity, a sub-domain of cultural competency; it has also been identified as a factor that influences cultural competence $^{14-16)}$.

Cultural competence is a critical aspect required to adapt to the changing multicultural society; foreign studies $^{17)}$ also conclude that dental hygiene students should be ready to provide high-quality services for patients with culturally diverse backgrounds. However, to our knowledge, there have been no studies on cultural competence in dental hygiene students or dental hygienists; moreover, the understanding of the need for cultural competence is also lacking. As such, this study aimed to identify the factors influencing critical thinking disposition and empathy on cultural competency, to strengthen the cultural competency of dental hygiene students, and to provide a foundation for the development of convergent curricula.

\section{Materials and Methods}

\section{Subjects and methods}

This study randomly sampled first, second, and third-year dental hygiene students in two schools in Gyeonggi-do and Chungcheongnam-do. The research took place between September 1 and September 30, 2017; the subjects were notified of the objective and background of this study, explained that their responses were confidential and only used for the purposes of this study, and then the researcher collected the self-administered surveys from students who had provided written consent. The calculation of sample size utilized $\mathrm{G}^{*}$ Power 3.1 with following parameters: significance level of 0.05, statistical power of 0.95 , and effect size of 0.15 , a medium-level for regression analysis, leading to 446 individuals required for regression analysis; this study assumed a defect rate of $20 \%$ and collected a total of 529 surveys for analysis. This study was performed after obtaining the approval from the Institutional Ethics Board of Suwon Science College (IRB2-7008167-AB-N-01-201706-HR-002-01).

\section{Research tools}

\section{1) General characteristics}

A total of 10 general characteristics were surveyed, including subject sex, age, grade, religion, economic level, foreign visiting experience, existence of a foreign friend, foreign residents of family or relatives, foreign language skills, and multicultural educational experience.

\section{2) Critical thinking}

Critical thinking was measured using a scale developed by Kwon et al. ${ }^{18)}$, comprising 35 items covering eight sub-domains, including intellectual integration (six items), creativity (four items), challenge-seeking (six items), openness (three items), prudence (four items), objectivity (four items), truth-seeking (three items), and exploring (five items). The items were measured based on a 


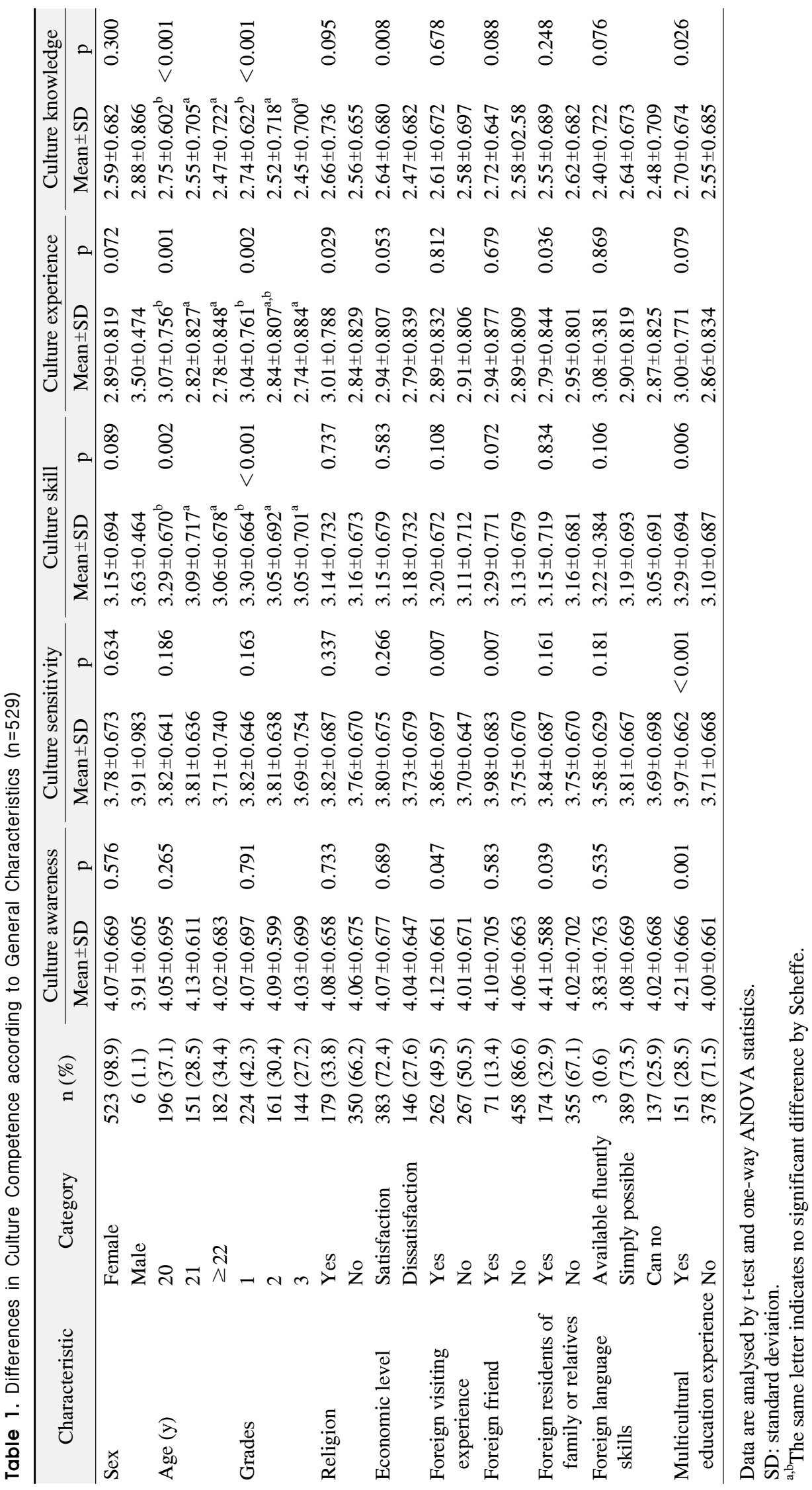


five-point Likert scale, ranging from 1 point ('not at all') to 5 points ('very much so'). The reliability of the study tool has a Cronbach's $\alpha=0.864$.

\section{3) Empathic ability}

Empathic ability was measured using the Interpersonal Reactivity Index developed by Davis ${ }^{19)}$ and translated into Korean by Kang et al. ${ }^{20)}$, which is composed of 28 items in four sub-domains, including seven items each in perspective-taking, fantasy factor, empathic concern, and personal distress. The items were measured based on a five-point Likert scale, ranging from 1 point ('not at all') to 5 points ('very much so'). The reliability of the study tool had a Cronbach's $\alpha=0.826$.

\section{4) Cultural competency}

Cultural competency was measured using a scale developed by Han and Cho Chung $^{21)}$, with 27 items covering five sub-domains, including cultural awareness (four items), cultural sensitivity (four items), culture skill (six items), culture experience (four items), and culture knowledge (nine items). The items were measured based on a five-point Likert scale, ranging from 1 point ('not at all') to 5 points ('very much so'), with higher points indicating higher cultural competency. The reliability of the study tool had a Cronbach's $\alpha=0.908$.

\section{Data analysis}

The collected data were analyzed using PASW Statistics for Windows (ver. 18.0; IBM Co., Armonk, NY, USA). The general characteristics were analyzed using frequency analysis for critical thinking and empathic ability, while averages and standard deviations were obtained for cultural competency. The cultural competency depending on general characteristics was subjected to t-tests and one-way analysis of variance (ANOVA); Levene statistics were used for the homogeneity of variance tests and Scheffe post-hoc tests were conducted to confirm significant differences between groups. Pearson's correlation analysis was conducted to examine the relationship between critical thinking, empathic ability, and cultural competency; multiple regression analysis was conducted to identify factors affecting cultural competency. The significance level of all statistics was set at 0.05 .

\section{Results}

\section{Differences in cultural competency according to general characteristics}

The differences in cultural competency according to general characteristics indicated that lower age and grade led to higher culture skill, experience, and knowledge $(\mathrm{p}<$ 0.01 ) and that culture experience was high in the presence of religion. Satisfaction with economic level was associated with a higher culture knowledge and experience of visiting overseas was associated with a higher cultural awareness and cultural sensitivity $(p<0.05)$. The presence of a foreign friend was associated with a higher cultural sensitivity, while the presence of family or relatives residing overseas was associated with higher cultural awareness and culture experience $(p<0.05)$. Experience with multicultural education was associated with higher cultural awareness, sensitivity, skill, and knowledge, with statistically significant differences $(\mathrm{p}<$

Table 2. Level of Critical Thinking Disposition, Empathic and Culture Competency $(n=529)$

\begin{tabular}{cc}
\hline \multicolumn{1}{c}{ Variable } & Mean \pm SD \\
\hline Critical thinking disposition & $3.23 \pm 0.372$ \\
Intellectual integration & $3.64 \pm 0.620$ \\
Creativity & $3.09 \pm 0.783$ \\
Conductivity & $2.89 \pm 0.611$ \\
Openness & $3.40 \pm 0.638$ \\
Prudence & $3.01 \pm 0.547$ \\
Objectivity & $3.16 \pm 0.522$ \\
Truth seeking & $3.38 \pm 0.631$ \\
Exploration castle & $3.27 \pm 0.610$ \\
Empathic ability & $3.49 \pm 0.395$ \\
Perspective-taking & $3.67 \pm 0.556$ \\
Fantasy scale & $3.50 \pm 0.186$ \\
Empathic concern & $3.42 \pm 0.436$ \\
Personal distress & $3.37 \pm 0.453$ \\
Culture competency & $3.30 \pm 0.472$ \\
Culture awareness & $4.06 \pm 0.668$ \\
Culture sensitivity & $3.78 \pm 0.676$ \\
Culture skill & $3.16 \pm 0.693$ \\
Culture experience & $2.90 \pm 0.818$ \\
Culture knowledge & $2.60 \pm 0.684$ \\
\hline
\end{tabular}

SD: standard deviation. 
0.05; Table 1).

2. Levels of critical thinking, empathic ability, and cultural competency

Among the sub-domains of critical thinking, intellectual integration was highest, with a score of 3.64, while and challenge-seeking was lowest at 2.89. Among sub-domains of empathic ability, perspective-taking was highest, with a score of 3.67; cultural awareness was the highest sub-domain of cultural competency at 4.06 , while culture knowledge was the lowest at 2.60 (Table 2).

3. Correlation between critical thinking, empathic ability, and cultural competency

The analysis of the correlation between critical thinking, empathic ability, and cultural competency is shown in Table 3. All sub-domains of cultural competency (cultural awareness, cultural sensitivity, culture skill, culture experience, and culture knowledge) were correlated with critical thinking $(\mathrm{p}<0.001)$; among these, cultural sensitivity showed the highest correlation, at 0.325 . Among the sub-domains of cultural competency, cultural awareness, cultural sensitivity, culture skill, and culture experience were correlated with empathic ability; among these, cultural awareness had the highest correlation, at 0.367 ( $<<0.001$; Table 3).

\section{Factors influencing cultural competency}

The factors influencing the sub-domain of cultural awareness included intellectual integration, openness, prudence, and perspective-taking $(\mathrm{p}<0.001)$, with an explanatory power of $22.4 \%$. The factors influencing cultural sensitivity included intellectual integration, challenge-seeking, openness, and empathic concern, with an explanatory power of $19.4 \%(\mathrm{p}<0.001)$. The factors influencing culture skill included intellectual integration, creativity, and challenge-seeking $(\mathrm{p}<0.001)$. The factors influencing culture experience included prudence, objectivity, perspective-taking, and personal distress $(\mathrm{p}<0.001)$. The factors influencing culture knowledge included creativity and challenge-seeking, with statistically significant differences $(\mathrm{p}<0.001)$. Multicollinearity was tested using tolerance and variance inflation factor (VIF) values; the tolerance was below 0.1 and VIF was smaller than 10, indicating that no variables had issues of multicollinearity (Table 4).

\section{Discussion}

This study was conducted to confirm the influence of critical thinking and empathic ability on cultural competency in dental hygiene students and to contribute to increased future multicultural competency.

The levels of critical thinking, empathic ability, and cultural competency of the subjects were $3.23,3.49$, and 3.30 , respectively. Song et al. ${ }^{7)}$ studied nursing students, reporting levels of $3.53,3.73$, and 3.23 , showing a slight difference compared to those in the present study. The present study examined the sub-domains of critical thinking, which indicated higher intellectual integration

Table 3. Correlation between Critical Thinking, Empathy, and Culture Competence $(n=529)$

\begin{tabular}{lccccccc}
\hline & CTD & EA & CA & CSe & CS & CE & CK \\
\hline CTD & 1 & & & & & & \\
EA & $0.222^{* * *}$ & 1 & & & & & \\
CA & $0.291^{* * *}$ & $0.367^{* * *}$ & 1 & & & \\
CSe & $0.325^{* * *}$ & $0.320^{* * *}$ & $0.651^{* * *}$ & 1 & & \\
CS & $0.323^{* * *}$ & $0.147^{* *}$ & $0.221^{* * *}$ & $0.412^{* * *}$ & 1 & 1 \\
CE & $0.191^{* * *}$ & $0.096^{*}$ & 0.001 & $0.174^{* * *}$ & $0.574^{* * *}$ & $0.483^{* * *}$ & 1 \\
CK & $0.167^{* * *}$ & 0.983 & -0.056 & $0.111^{*}$ & $0.465^{* * *}$ & 0 \\
\hline
\end{tabular}

Data are analysed by Pearson correlation statistics.

CTD: critical thinking disposition, EA: empathic ability, CA: culture awareness, CSe: culture sensitivity, CS: culture skill, CE: culture experience, $\mathrm{CK}$ : culture knowledge. ${ }^{*} \mathrm{p}<0.05,{ }^{* *} \mathrm{p}<0.01,{ }^{* * *} \mathrm{p}<0.001$ 
Table 4. Factors Affecting Culture Competence of Subjects $(n=529)$

\begin{tabular}{|c|c|c|c|c|c|}
\hline Variable & $\mathrm{B}$ & SE & $\beta$ & $\mathrm{t}$ & $\mathrm{p}$ \\
\hline \multicolumn{6}{|l|}{ Culture awareness } \\
\hline Intellectual integration & 0.190 & 0.053 & 0.176 & 3.573 & $<0.001$ \\
\hline Openness & 0.161 & 0.045 & 0.154 & 3.540 & $<0.001$ \\
\hline Prudence & -0.118 & 0.057 & -0.097 & -2.055 & 0.040 \\
\hline Perspective-taking & 0.162 & 0.064 & 0.135 & 2.527 & 0.012 \\
\hline \multicolumn{6}{|c|}{$\mathrm{F}=12.446, \mathrm{R}^{2}=0.224$, adjusted $\mathrm{R}^{2}=0.206, \mathrm{p}<0.001$} \\
\hline \multicolumn{6}{|l|}{ Culture sensitivity } \\
\hline Intellectual integration & 0.144 & 0.055 & 0.132 & 2.628 & 0.009 \\
\hline Conductivity & 0.142 & 0.050 & 0.128 & 2.870 & 0.004 \\
\hline Openness & 0.127 & 0.047 & 0.120 & 2.713 & 0.007 \\
\hline Empathic concern & 0.186 & 0.088 & 0.120 & 2.102 & 0.036 \\
\hline \multicolumn{6}{|c|}{$\mathrm{F}=10.345, \mathrm{R}^{2}=0.194$, adjusted $\mathrm{R}^{2}=0.175, \mathrm{p}<0.001$} \\
\hline \multicolumn{6}{|l|}{ Culture skill } \\
\hline Intellectual integration & 0.153 & 0.058 & 0.137 & 2.628 & 0.009 \\
\hline Creativity & 0.104 & 0.040 & 0.118 & 2.589 & 0.010 \\
\hline Conductivity & 0.128 & 0.053 & 0.113 & 2.434 & 0.015 \\
\hline \multicolumn{6}{|c|}{$\mathrm{F}=6.490, \mathrm{R}^{2}=0.131$, adjusted $\mathrm{R}^{2}=0.111, \mathrm{p}<0.001$} \\
\hline \multicolumn{6}{|l|}{ Culture experience } \\
\hline Prudence & -0.163 & 0.076 & -0.109 & -2.144 & 0.033 \\
\hline Objectivity & 0.179 & 0.081 & 0.114 & 2.201 & 0.028 \\
\hline Perspective-taking & -0.212 & 0.085 & -0.144 & -2.501 & 0.013 \\
\hline Personal distress & 0.382 & 0.101 & 0.212 & 3.793 & $<0.001$ \\
\hline \multicolumn{6}{|c|}{$\mathrm{F}=4.296, \mathrm{R}^{2}=0.091$, adjusted $\mathrm{R}^{2}=0.070, \mathrm{p}<0.001$} \\
\hline \multicolumn{6}{|l|}{ Culture knowledge } \\
\hline Creativity & 0.094 & 0.042 & 0.107 & 2.254 & 0.025 \\
\hline Conductivity & 0.140 & 0.054 & 0.125 & 2.577 & 0.010 \\
\hline \multicolumn{6}{|c|}{$\mathrm{F}=2.237, \mathrm{R}^{2}=0.049$, adjusted $\mathrm{R}^{2}=0.027, \mathrm{p}=0.009$} \\
\hline
\end{tabular}

Data are analysed by multiple regression statistics.

and openness and lower challenge-seeking and prudence. Dental hygiene students had the ability to amass data on problems and situations and comprehensively consider them; it appears that they are able to accept a variety of perspectives and have a high level of openness ${ }^{18)}$, in which they admit to their errors and biases. Critical thinking is required in the application, analysis, organization, and deduction used in dental hygiene work, and also enables effective decision-making and logical communication. Therefore, to secure cultural competency, it is important to secure two main areas of challenge-seeking, which involves persistence and continuing to try new things, and prudence ${ }^{18)}$, which involves securing sufficient evidence and validity. Empathic ability is an emotional aspect that involves an understanding and consideration of the other individual. The level of empathic ability leads to differences in cultural competency that is related to other cultures. Higher empathic ability leads to an understanding and respecting of other cultures based on one's own ${ }^{6,22)}$; as such, empathic ability is often seen as a predictor of cultural competency ${ }^{23)}$. Among its sub-domains, perspective-taking had the highest scores. It appears that dental hygiene students have a high tendency to think from someone else's perspective. Among sub-domains of cultural competency, cultural awareness was the highest and cultural knowledge was the lowest. The majority of studies on nursing students, such as those by Park ${ }^{12)}$ and $\mathrm{Han}^{8)}$, showed similar results ${ }^{1,21,24)}$. Lower cultural knowledge appears to be due to a lack of education in the Korean educational system regarding exposure to multiple cultures, and the topic is also not covered in the dental hygiene process. Cultural competency is not built overnight ${ }^{7)}$. Dental hygiene students are upcoming dental hygienists who perform 
dental hygiene work on peoples of multiple cultures. Therefore, education is required to improve cultural knowledge; the levels of knowledge should be continuously checked and weaknesses overcome.

The differences in cultural competency from general characteristics indicated that lower age and grade and the presence of religion led to higher levels of culture skill, experience, and knowledge. These results are concordant with those reported by Park $^{12)}$. Moreover, cultural competency was high when subjects had foreign friends, when their family or relatives resided overseas, or if they had experience with multicultural education. Multiple studies have reported that the experience of communication and experience with multiple cultures such as visiting or living in other countries, having foreign friends, familiarity with foreign languages, and experience with multicultural education have positive influences on cultural competency $5,6,15,16,24)$. However, the present study did not observe a particular difference based on the level of foreign language skill. For dental hygienists, the ability to communicate is critical to identify and treat problems and to educate patients. The inability to speak the language renders it impossible for the practitioner to relieve the tensions of patients and form a treatment relationship. Moreover, it may also lead to inappropriate oral care as the patient also lacks understanding of the treatment and fails to create a relationship of trust with the medical staff. Therefore, multicultural education and experience, as well as foreign language skills, are critical in dental hygiene education.

This study confirmed the correlation between critical thinking and cultural competency; this finding indicated that all sub-domains of critical thinking were related to cultural competency. Empathic ability was related to cultural awareness, sensitivity, skills, and experience. Cho et al. ${ }^{15)}$ observed correlations between cultural awareness, sensitivity, and experience. Lee and Lee ${ }^{1)}$ also found that empathic ability was correlated with cultural knowledge and skill. Along with the results of other studies, this study confirmed that critical thinking and empathic ability were basic elements of cultural competency ${ }^{1,12,15,16)}$.

This study also identified variables influencing the sub-domains of cultural competency, in which all sub- domains of critical thinking influenced cultural competency. Particularly, intellectual integration influenced cultural awareness, sensitivity, and skill, while challengeseeking influenced cultural sensitivity, skills, and knowledge. Moreover, creativity, openness, prudence, and objectivity all had influence; this led to the conclusion that critical thinking training, involving flexible and proactive responses and reflective thinking abilities are important in securing cultural competency.

The sub-domains of empathic ability, including perspective-taking, empathic concern, and personal distress, influenced cultural awareness, sensitivity, and experience. The dental hygiene students were able to accept perspectives and develop empathic concern by understanding and responding to the perspectives of other cultures. Empathic ability accepts and sensitively responds to cultural differences and significantly influences cultural competency ${ }^{6}$. It is important to develop educational programs to improve and complete empathic ability through methods such as field education.

As this study utilized convenient sampling of a specific group of dental hygiene students, it is difficult to generalize the results; in addition, another limitation is that it is a cross-sectional study on cultural competency, critical thinking disposition, and empathic ability. However, this study is significant as it focuses on a modern-day task of cultural competency when today's society demands cultural convergence in the dental hygiene industry. We expect that this study will be used as basic information for the development of multicultural curriculum in dental hygiene.

\section{References}

1. Lee JK, Lee CJ: The factors affecting social worker's cultural competence. Soc Sci Res 28: 183-204, 2012.

2. Ministry of Justice: Refugee Statistics for 2016. Retrieved October 5, 2017, from http://www.moj.go.kr/HP/COM/bbs _03/ShowData.do?strNbodCd=noti0097\&strWrtNo=220\& strAnsNo=A\&strFilePath=moj/\&strRtnURL=MOJ_404020 00\&strOrgGbnCd=104000(2017, February 7).

3. Statistics Korea: e-Country Index. Retrieved October 4, 2017, from http://www.index.go.kr/potal/main/EachDtlPageDetail. 
do?idx_cd=2756(2017).

4. Gangnam Medical Tour Center: Foreigner Patient Attraction Business. Retrieved October 5, 2017, from http://medicaltour. gangnam.go.kr/content $/ 28 /$ view.do?lang $=$ ko\&cid=28\&mid= 4-28(2017).

5. Chae DH, Park YH, Kang KH, Lee TH: A study on factors affecting cultural competency of general hospital nurses. J Korean Acad Nurs Adm 18: 76-86, 2012. https://doi.org/10.11111/jkana.2012.18.1.76

6. Seo YS, Kwon YC: Factors influencing to the cultural competence in nursing students. J Digit Converg 12: 415-423, 2014. https://doi.org/10.14400/JDC.2014.12.6.415

7. Song EJ, Yang YK, Park SK: Effects on critical thinking disposition and empathy on cultural competency in nursing students. J Korean Acad Psychiatr Ment Health Nurs 25: 347-355, 2016. https://doi.org/10.12934/jkpmhn.2016.25.4.347

8. Han SY: Factors influencing to the cultural competence in nursing students. J Learn Center Curric Instr 16: 73-86, 2016.

9. Campinha-Bacote J: The process of cultural competence in the delivery of healthcare services: a model of care. J Transcult Nurs 13: 181-184; discussion 200-201, 2002. https://doi.org/10.1177/10459602013003003

10. Choi $\mathrm{H}$ : Critical thinking, multiculturalism, and the education of humanities. J Humanit 32: 293-317, 2011.

11. Jeong $\mathrm{CH}$ : A study on meaning and important of critical thinking education in the multicultural society. Theory Prac Educ 20: 132-158, 2015.

12. Park SY: Relationship between self-reflection, critical thinking disposition, multicultural experience and cultural competence in nursing students. J Digit Converg 14: 345-355, 2016. https://doi.org/10.14400/JDC.2016.14.12.345

13. Wilkins EM: Clinical Practice of the Dental Hygiene. 10th ed. Lippintcott Williams \& Wilkins, Philadelphia, pp.37-59, 2009.
14. Jeffrey CL: Empathy and competence. Med J Aust 188: 414-416, 2008.

15. Cho MK, Shin IN, Lee YJ, et al.: University nursing students' empathic ability and cultural competency. Perspect Nurs Sci 12: 106-114, 2015.

16. Yang SY, Lim HN, Lee JH: The study on relationship between cultural competency and empathy of nursing students. J Korean Acad Soc Nurs Educ 19: 183-193, 2013. https://doi.org/10.5977/jkasne.2013.19.2.183

17. Fitch P: Cultural competence and dental hygiene care delivery: integrating cultural care into the dental hygiene process of care. J Dent Hyg 78: 11-21, 2004.

18. Kwon IS, Lee GE, Kim GD, et al.: Development of a critical thinking disposition scale for nursing students. J Korean Acad Nurs 36: 950-958, 2006. https://doi.org/10.4040/jkan.2006.36.6.950

19. Davis $\mathrm{MH}$ : A multidimensional approach to individual differences in empathy. American Psychological Association, Washington, 1980.

20. Kang I, Kee S, Kim SE, et al.: Reliability and validity of the Korean-version of interpersonal reactivity index. J Korean Neuropsychiatr Assoc 48: 352-358, 2009.

21. Han SY, Cho Chung HI: Development of a cultural competence scale for nursing students. J Korean Acad Nurs 45: 684-693, 2015. https://doi.org/10.4040/jkan.2015.45.5.684

22. Oh WO: Factors influencing cultural sensitivity among nursing students. J Korean Acad Child Health Nurs 17: 222-229, 2011.

23. Yang SY: The study on relationship between characteristics of cultural exchanges, self-efficacy, and cultural competency of nursing students. J Korea Contents Assoc 14: 334-345, 2014. https://doi.org/10.5392/JKCA.2014.14.07.334

24. Choi HJ: Exploratory study on experience in multiculture and cultural competence of service providers in multicultural settings. Ment Health Soc Work 37: 405-439, 2011. 